\title{
Chemoselective Hydrogenation of Aldehydes under Mild, Base-Free Conditions: Manganese Outperforms Rhenium
}

\author{
Mathias Glatz, ${ }^{\dagger}$ Berthold Stöger, $^{\S}$ Daniel Himmelbauer, ${ }^{\dagger}$ Luis F. Veiros, ${ }^{\dagger}$ and Karl Kirchner*, ${ }^{\dagger}$ (†) \\ ${ }^{\dagger}$ Institute of Applied Synthetic Chemistry and ${ }^{\S}$ X-Ray Center, Vienna University of Technology, Getreidemarkt 9, A-1060 Vienna, \\ Austria \\ ‡Centro de Química Estrutural, Instituto Superior Técnico, Universidade de Lisboa, Av. Rovisco Pais No. 1, 1049-001 Lisboa, \\ Portugal
}

\section{Supporting Information}

ABSTRACT: Several hydride $\mathrm{Mn}(\mathrm{I})$ and $\operatorname{Re}(\mathrm{I})$ PNP pincer complexes were applied as catalysts for the homogeneous chemoselective hydrogenation of aldehydes. Among these, $\left[\mathrm{Mn}(\mathrm{PNP}-i \mathrm{Pr})(\mathrm{CO})_{2}(\mathrm{H})\right]$ was found to be one of the most efficient base metal catalysts for this process and represents a rare example which permits the selective hydrogenation of aldehydes in the presence of ketones and other reducible functionalities, such as $\mathrm{C}=\mathrm{C}$ double bonds, esters, or nitriles. The reaction proceeds at room temperature under base-free conditions with catalyst loadings between 0.1 and $0.05 \mathrm{~mol} \%$ and a hydrogen pressure of $50 \mathrm{bar}$ (reaching TONs of up to 2000). A mechanism which involves an outer-sphere hydride transfer and reversible PNP ligand deprotonation/protonation is proposed. Analogous isoelectronic and isostructural $\operatorname{Re}(\mathrm{I})$ complexes were only poorly active.

KEYWORDS: hydrogenation, aldehydes, manganese, pincer complexes, DFT calculations

\section{INTRODUCTION}

One environmentally friendly and sustainable method to prepare alcohols, which are valuable commodities for a large number of fine and bulk chemicals, is the catalytic hydrogenation of carbonyl compounds with dihydrogen. ${ }^{1}$ Over the years, many highly efficient and active homogeneous catalysts based on precious but also non-precious metals have been described for this purpose (Scheme 1). ${ }^{2}$ Especially catalysts which reveal full selectivity for aldehydes over ketones and/or alkenes ${ }^{3,4}$ are of

Scheme 1. Well-Defined Catalysts for the Chemoselective Hydrogenation of Aldehydes

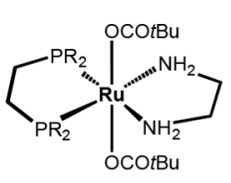

$$
\mathrm{R}=\mathrm{Ph}
$$
Dupau (2015)

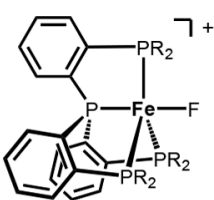

$\mathrm{R}=\mathrm{Ph}$ Beller (2013)

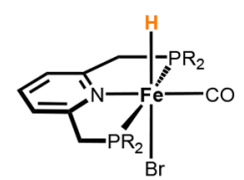

$\mathrm{R}=i \mathrm{Pr}$ Milstein (2014)

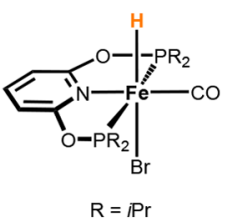

$\mathrm{R}=\operatorname{Pr}$ Hu (2015)

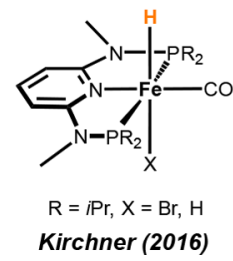

practical importance for the synthesis of flavors, ${ }^{5}$ fragrances, ${ }^{3}$ and pharmaceuticals. $^{6}$

In the past couple of years, the development and advancement of hydrogenation catalysts based on earth-abundant, inexpensive non-precious metals experienced tremendous progress. ${ }^{7}$ In particular, iron- and manganese-based catalysts turned out to be highly active for the hydrogenation of carbonyl compounds, imines, and nitriles (Scheme 2)..$^{8-11}$ In the case of manganese, however, most hydrogenations proceed at relatively high catalyst loadings and elevated temperatures and, in addition, require large amounts of strong bases as additives. As yet, only iron-based systems proved to be reasonably chemoselective for the reduction of aldehydes, as shown in Scheme $1 .{ }^{12-14}$ We recently described the application of $\left[\mathrm{Fe}\left(\mathrm{PNP}^{\mathrm{Me}}-\mathrm{Pr}\right)(\mathrm{CO})(\mathrm{H})(\mathrm{Br})\right]$ and $\left[\mathrm{Fe}\left(\mathrm{PNP}^{\mathrm{Me}}-i \mathrm{Pr}\right)(\mathrm{H})_{2}(\mathrm{CO})\right]$ as highly active catalysts for the homogeneous hydrogenation of aldehydes (Scheme 1). ${ }^{15,16}$

In this paper, we describe an experimental and theoretical investigation of the chemoselective hydrogenation of aldehydes with dihydrogen using several hydride $\mathrm{Mn}(\mathrm{I})$ and $\operatorname{Re}(\mathrm{I})$ PNP pincer complexes as catalysts (Scheme 3 ). To the best of our knowledge, this is the first example of an efficient manganesebased selective hydrogenation of aldehydes which proceeds under mild and base-free conditions with low catalyst loadings. It

Received: January 12, 2018

Revised: $\quad$ March 20, 2018

Published: April 2, 2018 
Scheme 2. Manganese Catalysts for the Hydrogenation of Ketones and Aldehydes

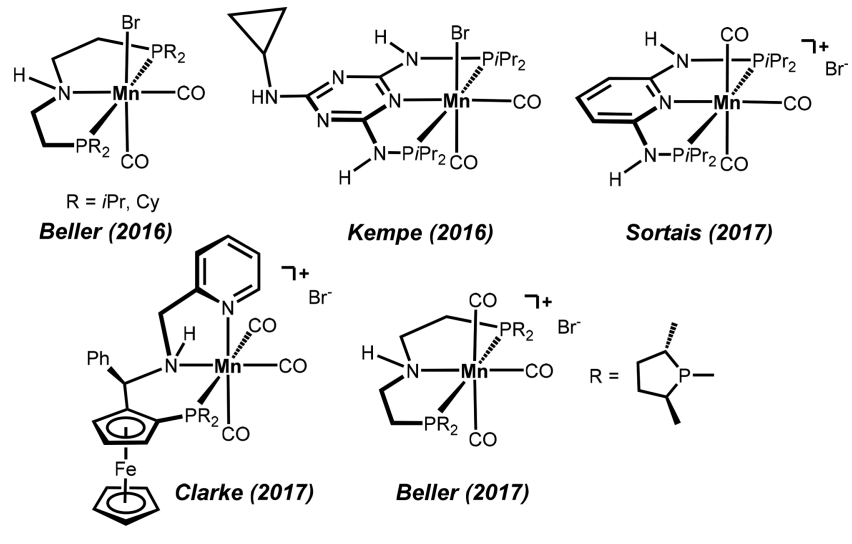

Scheme 3. PNP Pincer Complexes Tested as Catalysts for the Hydrogenation of Aldehydes $(\mathrm{R}=i \mathrm{Pr})$ and Structural View of Re1 Showing 30\% Thermal Ellipsoids ${ }^{a}$
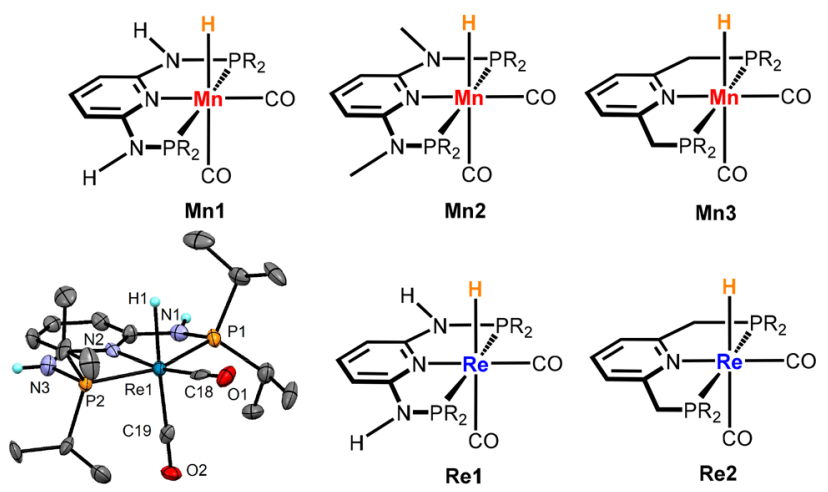

${ }^{a}$ Selected bond lengths $(\AA)$ and angles $\left(^{\circ}\right)$ : Re1-P1 2.347(3), Re1P2 2.342(3), Re1-N2 2.162(8), Re1-C18 1.87(1), Re1-C19 1.94(1), Re1-H1 1.91(5), P1-Re1-P2 158.2(1).

has to be noted that Re pincer complexes have rarely been used in (de)hydrogenation catalysis. ${ }^{17,18}$

\section{RESULTS AND DISCUSSION}

The reaction of $\left[\mathrm{M}(\mathrm{CO})_{5} \mathrm{X}\right](\mathrm{M}=\mathrm{Mn}, \mathrm{X}=\mathrm{Br} ; \mathrm{M}=\mathrm{Re}, \mathrm{X}=\mathrm{Cl})$ with the respective PNP pincer ligands in dioxane at elevated temperatures afforded the neutral biscarbonyl complexes $\left[\mathrm{M}(\mathrm{PNP})(\mathrm{CO})_{2} \mathrm{X}\right](\mathbf{1 - 5})$ (Scheme 4). Treatment of these intermediates with $\mathrm{Na}\left[\mathrm{HBEt}_{3}\right]$ (1.1 equiv) in toluene afforded complexes Mn1, Mn2, Mn3, Re1, and Re2. The synthesis of Mn1 and Mn2 was already reported previously. ${ }^{19}$ All new complexes could be isolated in 77-95\% isolated yields and were fully characterized by a combination of elemental analysis, ${ }^{1} \mathrm{H}$, ${ }^{13} \mathrm{C}\left\{{ }^{1} \mathrm{H}\right\}$, and ${ }^{31} \mathrm{P}\left\{{ }^{1} \mathrm{H}\right\}$ NMR, and IR spectroscopy (see Supporting Information (SI)). In addition, the molecular structure of $\operatorname{Re} 1$ was determined by X-ray crystallography (Scheme 3, bottom left).

The catalytic performance of Mn1, Mn2, Mn3, Re1, and Re2 was then investigated for the hydrogenation of aldehydes. The experiments were performed in EtOH as solvent using 4fluorobenzaldehyde as model substrate to find the most active catalyst and optimal hydrogenation reaction conditions (Table 1 ). No reaction took place in aprotic solvents such as THF or toluene at 50 bar $\mathrm{H}_{2}$, a catalyst loading of $1.0 \mathrm{~mol} \%$, and a reaction time of $18 \mathrm{~h}$. In the absence of dihydrogen, the
Scheme 4. Synthesis of Hydride Mn(I) and Re(I) PNP Pincer Complexes

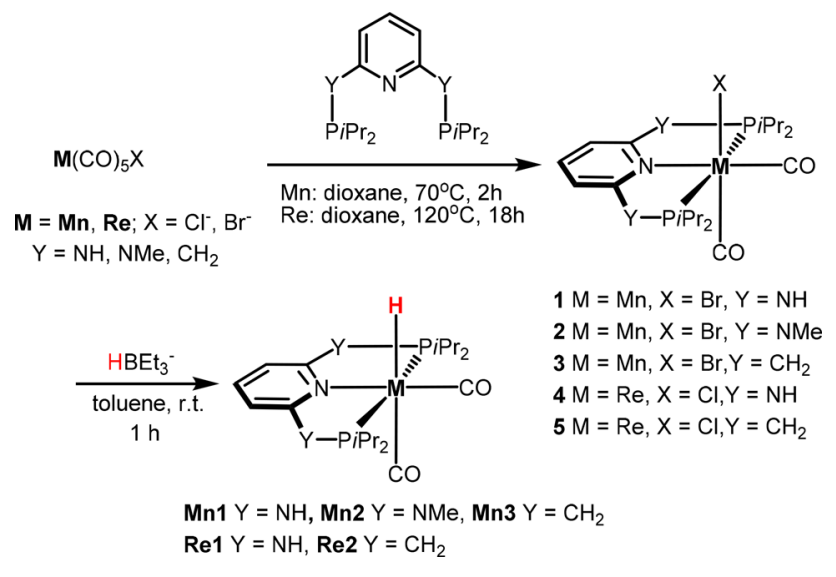

hydrogenation of 4-fluorobenzaldehyde to yield 4-fluorobenzyl alcohol was not observed-no reaction took place. Thus, a possible transfer-hydrogenation mechanism in EtOH could be excluded. It has to be further emphasized that ketones, e.g., acetophenone and 4-fluoroacetophenone, did not react with any of the catalysts tested under the same reaction conditions described below.

When Mn1 (0.1 mol\%) was used as catalyst, complete conversion was observed after $4 \mathrm{~h}$ under a hydrogen pressure of 30 bar (Table 1, entry 4). By lowering the catalyst loading to 0.05 mol\%, quantitative conversion was achieved after $18 \mathrm{~h}$ at a hydrogen pressure of 50 bar (Table 1 , entry 5 ). If the reaction was performed in the presence of 3 equiv of DBU (1,8-diazabicyclo[5.4.0] undec-7-ene) as external base, 4-fluorobenzyl alcohol was obtained in $52 \%$ yield after $48 \mathrm{~h}$ under a hydrogen pressure of 50 bar and a catalyst loading of $0.005 \mathrm{~mol} \%$ (Table 1 , entry 6). This corresponds to a turnover number (TON) of 10400. Complexes Mn2 and Mn3 showed no or poor reactivity, even with a catalyst loading of $1 \mathrm{~mol} \%$ (Table 1, entries 7 and 8). Surprisingly, the $\operatorname{Re}(\mathrm{I})$ complexes $\operatorname{Re} 1$ and $\operatorname{Re} 2$ with 1 mol\% catalyst loadings were poorly active, affording only 45 and $76 \%$, respectively, of 4-fluorobenzyl alcohol (Table 1, entries 9 and 11). At $50{ }^{\circ} \mathrm{C}$, 4-fluorobenzyl alcohol was obtained in $95 \%$ yield (Table 1, entry 10).

Once Mn1 was determined to be the most active catalyst and its general applicability proved, various substrates were been tested to establish scope and limitations (Table 2). The catalytic experiments were conducted in the presence of $0.1-0.05 \mathrm{~mol} \%$ of catalyst at $25^{\circ} \mathrm{C}$ and 50 bar hydrogen pressure, for a reaction time of $18 \mathrm{~h}$, without addition of any additives. The best results could be obtained for aromatic aldehydes bearing electronwithdrawing halogen substituents as well as electron-donating groups such as 4-anisaldehyde and 4-tolylaldehyde on the phenyl ring (Table 2, A1-A5) where catalyst loadings of $0.05 \mathrm{~mol} \%$ were employed. Heteroaromatic substrates as well as aliphatic aldehydes could be reduced quantitatively under the same reaction conditions but with a catalyst loading of $0.1 \mathrm{~mol} \%$ (Table 2, A6-A17). Substrates with conjugated and nonconjugated $\mathrm{C}=\mathrm{C}$ double bonds were also selectively hydrogenated. For instance, citronellal or lyral, which are used in the flavor and fragrance industry (Table 2, A14-17), as well as the more challenging $\alpha, \beta$-unsaturated substrate cinnamaldehyde (Table 2, A12) were not hydrogenated. In order to investigate the catalyst's selectivity toward substrates with other unsaturated functionalities which can be easily hydrogenated, additional 
Table 1. Hydrogenation of 4-Fluorobenzaldehyde with Several Manganese and Rhenium Catalysts ${ }^{a}$

\begin{tabular}{|c|c|c|c|c|c|c|c|}
\hline entry & cat. & solvent & $\mathrm{S} / \mathrm{C}$ & $P$ (bar) & $t(\mathrm{~h})$ & conversion $(\%)^{b}$ & TON \\
\hline 1 & Mn1 & THF & 1000 & 50 & 18 & & \\
\hline 2 & Mn1 & toluene & 1000 & 50 & 18 & & \\
\hline 3 & Mn1 & $\mathrm{EtOH}$ & 1000 & 30 & 1 & 54 & 540 \\
\hline 4 & Mn1 & $\mathrm{EtOH}$ & 1000 & 30 & 4 & $>99$ & 1000 \\
\hline 5 & Mn1 & $\mathrm{EtOH}$ & 2000 & 50 & 18 & $>99$ & 2000 \\
\hline $6^{c}$ & Mn1 & $\mathrm{EtOH}$ & 20000 & 50 & 48 & 52 & 10400 \\
\hline 7 & Mn2 & $\mathrm{EtOH}$ & 100 & 50 & 18 & & \\
\hline 8 & Mn3 & $\mathrm{EtOH}$ & 100 & 50 & 18 & 21 & 21 \\
\hline 9 & $\operatorname{Re} 1$ & $\mathrm{EtOH}$ & 100 & 50 & 18 & 86 & 86 \\
\hline $10^{d}$ & $\operatorname{Re} 1$ & $\mathrm{EtOH}$ & 100 & 50 & 18 & 95 & 95 \\
\hline 11 & $\operatorname{Re} 2$ & $\mathrm{EtOH}$ & 100 & 50 & 18 & 76 & 76 \\
\hline
\end{tabular}

${ }^{a}$ Reaction conditions: catalysts $(0.4-20.0 \mu \mathrm{mol})$, 4-fluorobenzaldehyde $(2.0 \mathrm{mmol})$, EtOH $(4 \mathrm{~mL}), 50$ bar $\mathrm{H}_{2}, 25{ }^{\circ} \mathrm{C} .{ }^{b}$ Determined by ${ }^{19} \mathrm{~F}$ NMR spectroscopy. ${ }^{c}$ In the presence of DBU $\left(1.2 \mu \mathrm{mol}, 3\right.$ equiv). ${ }^{d}$ Performed at $50{ }^{\circ} \mathrm{C}$.

Table 2. Hydrogenation of Aldehydes A1-A17 with Catalyst Mn1 ${ }^{a, b}$

$$
\mathbf{R} \overbrace{0} \frac{\operatorname{Mn} 1(0.1-0.05 \mathrm{~mol} \%), \mathrm{H}_{2}(50 \mathrm{bar})}{\mathrm{EtOH}, 25^{\circ} \mathrm{C}, 18 \mathrm{~h}} \mathrm{R} \widehat{\mathrm{OH}}
$$
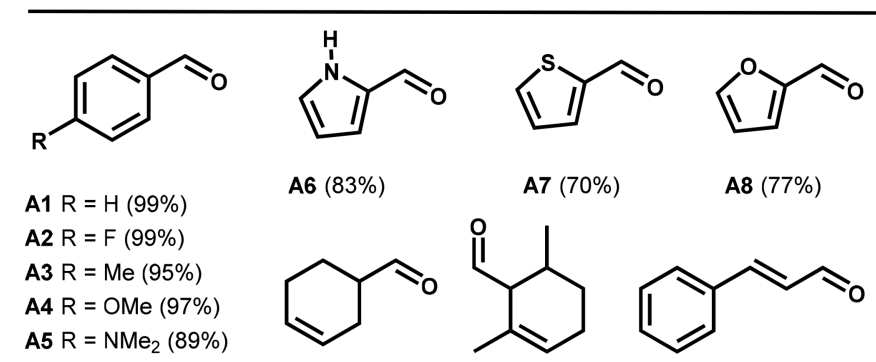

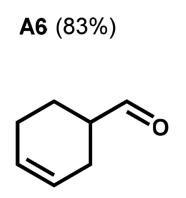<smiles>CC1=CCCC(C)C1C=O</smiles>
A10 (88\%) A11 (35\%)<smiles>O=C/C=C/c1ccccc1</smiles>
A12 (91\%)<smiles>CCCCCCCC=O</smiles><smiles>CC(C)=CCCC(C)CC=O</smiles><smiles>CC(C)=CCCC(C)CCOCC=O</smiles><smiles>CC(C=O)Cc1ccc2c(c1)OCO2</smiles><smiles>CC(C)(O)CCCC1=CCC(C=O)CC1</smiles>

A14 (85\%) A15 (75\%)

A16 (75\%)

A17 (55\%)

${ }^{a}$ Reaction conditions: A1-A5 (1.0 $\left.\mu \mathrm{mol}, 0.05 \mathrm{~mol} \% \mathrm{Mn1}\right)$, A6-A17 $(2.0 \mu \mathrm{mol}, 0.1 \mathrm{~mol} \% \mathrm{Mn} 1)$, aldehyde $(2 \mathrm{mmol}), \mathrm{EtOH}(4 \mathrm{~mL}), 50 \mathrm{bar} \mathrm{H}, 25$ ${ }^{\circ} \mathrm{C}, 18 \mathrm{~h} .{ }^{b}$ Yields (in parentheses) based on integration of ${ }^{1} \mathrm{H}$ spectra using mesitylene as internal standard.

studies were carried out. Competitive experiments were carried out using equimolar mixtures of 4-fluorobenzaldehyde and the respective co-substrates at a catalyst-to-substrate ratio of 1:1000 with respect to the aldehyde. These studies showed that ketones, esters, alkynes, and nitrile groups were not hydrogenated. Moreover, these functionalities also did not interfere with the hydrogenation of the aldehyde moieties.

Stoichiometric experiments show that Mn1 reacts readily with aldehydes, even in aprotic solvents such as benzene or THF. The addition of 1 equiv of 4-fluorobenzaldehyde to a solution of the $\mathrm{Mn}(\mathrm{I})$ hydride $\mathrm{Mn} \mathbf{1}$ in $\mathrm{C}_{6} \mathrm{D}_{6}$ revealed the formation of a new but minor manganese species (Scheme 5). The concentration of this compound did not change over time but grew with increasing amount of added substrate. Thus, addition of up to 20 equiv of aldehyde was required to observe complete conversion of the manganese hydride complex. The new compound was tentatively assigned as the alkoxide complex $\mathbf{6}$, generated by
Scheme 5. Reaction of Mn1 with 4-Fluorobenzaldehyde and 4-Fluoroacetophenone in $\mathrm{C}_{6} \mathrm{D}_{6}$

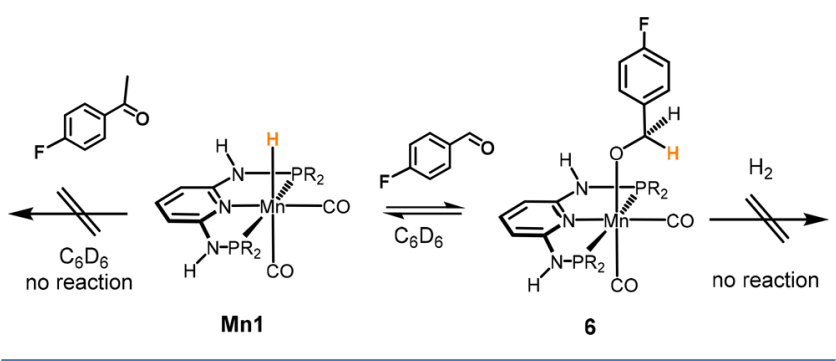

insertion of the aldehyde into the metal hydride bond of Mn1. Compound 6 could not be isolated and exhibited singlet resonances at 115.8 and $140.9 \mathrm{ppm}$ in the ${ }^{19} \mathrm{~F}\left\{{ }^{1} \mathrm{H}\right\}$ and ${ }^{31} \mathrm{P}\left\{{ }^{1} \mathrm{H}\right\}$ NMR spectra, respectively (free 4-fluorobenzyl alcohol exhibits a singlet at $116.1 \mathrm{ppm}$ in the ${ }^{19} \mathrm{~F}\left\{{ }^{1} \mathrm{H}\right\}$ NMR spectrum). In the IR 
spectrum, 6 displays the expected two signals of the symmetric and asymmetric CO stretching frequency at 1925 and $1848 \mathrm{~cm}^{-1}$ (cf. 1873 and $1790 \mathrm{~cm}^{-1}$ in $\mathrm{Mn} 1$ ). However, no further reaction took place when a benzene (or THF) solution of the in situgenerated alkoxide complex 6 was exposed to dihydrogen. There was also no catalytic reaction if a 3:1 mixture of THF/EtOH was used. Accordingly, EtOH as solvent is not required for the insertion step but obviously plays a crucial role in the subsequent dihydrogen activation step. Moreover, Mn1 did not react with 4fluoroacetophenone in both aprotic and protic solvents.

The reaction mechanism was explored in detail by means of DFT calculations. ${ }^{20}$ Benzaldehyde was taken as substrate and Mn1 (A in the calculations) as active catalyst. An explicit ethanol molecule (solvent) was considered, providing a proton shuttle and H-bond stabilization of the intermediates. Two different paths were considered, as shown in a simplified manner in Scheme 6 . The more likely one proceeds via participation of the

Scheme 6. Simplified Catalytic Cycles for Benzaldehyde Hydrogenation with $\mathrm{Mn}^{a}$

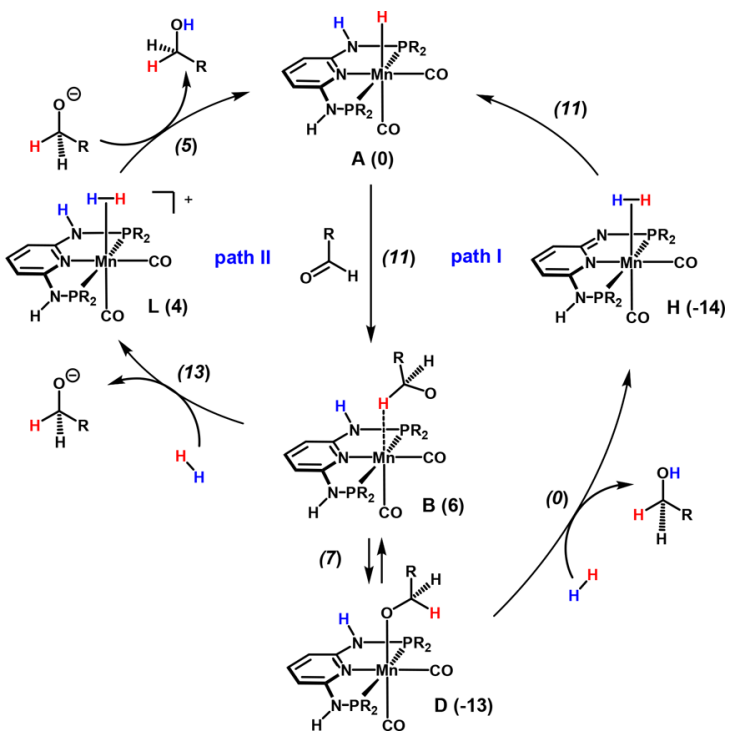

${ }^{a}$ Free energies in $\mathrm{kcal} / \mathrm{mol}$ are referred to $\mathbf{A}(\mathbf{M n} \mathbf{1}+\mathrm{EtOH}+$ benzaldehyde); transition state energies are given in italics; $\mathrm{R}=i \mathrm{Pr}$ ).

acidic $\mathrm{N}-\mathrm{H}$ bond of the PNP ligand in a bifunctional mechanism (path I). This is supported by the fact that catalyst Mn2, bearing NMe linkers, is catalytically inactive and $\mathbf{M n} 3$, featuring $\mathrm{CH}_{2}$ linkers which are less acidic than the $\mathrm{NH}$ linkers in $\mathbf{M n} \mathbf{1}$, is only poorly active (Table 1 , entry 8 ).

A reasonable mechanism has been established by means of DFT calculations. The free energy profile for path I is depicted in Figure 1. The first step is the attack of the hydride ligand in complex $\mathbf{A}$ to the carbonyl $\mathrm{C}$-atom of a free benzaldehyde molecule. The result is intermediate $\mathbf{B}$, a species with the resulting alkoxide weakly bonded to the metal by one $\mathrm{C}-\mathrm{H}$ bond. This is a fairly easy step with a barrier of $11 \mathrm{kcal} / \mathrm{mol}$ and a free energy balance of $\Delta G=6 \mathrm{kcal} / \mathrm{mol}$, indicating that $\mathbf{B}$ is less stable than the initial reactants. The alkoxide in $\mathbf{B}$ can easily leave the metal following a dissociative path, through intermediate $\mathbf{C}$. From here, the alkoxide may coordinate the metal by the $\mathrm{O}$ atom, forming $\mathbf{D}$ through an easy process involving proton exchange with the solvent (SI, Figure S1). Importantly, the alkoxide complex $\mathbf{D}$ is $13 \mathrm{kcal} / \mathrm{mol}$ more stable than the initial reagents and represents the catalyst resting state. Naturally, there can be proton exchange between the solvent, EtOH, and benzyl alkoxide. Thus, the subsequent species may be either one. Following the profile in Figure 1, the coordinated alkoxide in $\mathbf{D}$ is protonated by the $\mathrm{N}-\mathrm{H}$ proton of the PNP arm, with assistance of the ethanol molecule, from $\mathbf{D}$ to $\mathbf{E}$. This process has a barrier of $13 \mathrm{kcal} / \mathrm{mol}$ and is endergonic, with $\Delta G=7 \mathrm{kcal} / \mathrm{mol}$. Intermediate $\mathbf{F}$ is $3 \mathrm{kcal} / \mathrm{mol}$ more stable than the reactants and features a dearomatized PNP ligand. The HOMO and LUMO of complex $\mathbf{F}$ are depicted in Figure 2. The HOMO corresponds to the ligand $\pi$-system, with a significant contribution of the lone pair of the deprotonated $\mathrm{N}$-atom. The LUMO is essentially metal $z^{2}$ pointing toward the empty coordination position.

The reaction continues along the profile represented in Figure $3, \mathbf{F}^{\prime}$ being equivalent to $\mathbf{F}$ with a different relative orientation of the three molecules. Exchange of benzyl alcohol by one $\mathrm{H}_{2}$ molecule produces intermediate G. Dihydrogen coordination is facile, with a barrier of only $1 \mathrm{kcal} / \mathrm{mol}\left(\mathbf{T S}_{\mathrm{GH}}\right)$ in a clearly exergonic step, $\Delta G=-9 \mathrm{kcal} / \mathrm{mol}$. The resulting intermediate $\mathbf{H}$ is an $\eta^{2}-\mathrm{H}_{2}$ complex, which is $14 \mathrm{kcal} / \mathrm{mol}$ more stable than the initial reagents. Rearrangement of the $\mathrm{H}$-bond network between the $\mathrm{H}_{2}$ complex and the nearby ethanol molecule changes $\mathbf{H}$ into I. In the final step, there is splitting of the $\mathrm{H}-\mathrm{H}$ bond with reprotonation of the PNP N-atom and regeneration of the hydride ligand in $\mathbf{J}$, corresponding to the initial reactant $\mathbf{A}$ and an ethanol molecule. The last step is exergonic, with $\mathrm{J}$ being $25 \mathrm{kcal} / \mathrm{mol}$ more stable than A. Despite the presence of an ethanol molecule acting as a proton shuttle, the associated barrier is significant $\left(\Delta G^{+}=21 \mathrm{kcal} / \mathrm{mol}\right)$. The highest barrier along path $\mathrm{I}$ is $25 \mathrm{kcal} /$ mol, corresponding to the difference between intermediate $\mathbf{H}$, the most stable one, and transition state $\mathbf{T S}_{\mathrm{IJ}}$.

For comparison, the first step of the mechanism was also calculated for acetophenone as substrate. The barrier for the attack of the hydride ligand in complex $\mathbf{A}$ to the carbonyl $\mathbf{C}$-atom of a free acetophenone molecule is significantly higher than the one calculated for benzaldehyde (18 vs $11 \mathrm{kcal} / \mathrm{mol}$, respectively; SI, Figure S2). This trend is in accordance with the fact that ketones are not hydrogenated under the same reaction conditions. The remarkable substrate selectivity was recently also explained by the relative stability of alkoxide intermediates formed upon aldehyde insertion into the metal- $\mathrm{H}$ bond in the case of related iron PNP pincer complexes based on DFT calculations. $^{21}$ It has to be noted that the related $\mathrm{Mn}(\mathrm{I}) \mathrm{PNP}$ pincer complex $\left[\mathrm{Mn}(\mathrm{PNP}-i \mathrm{Pr})(\mathrm{CO})_{3}\right] \mathrm{Br}$ (Scheme 2) was shown to act as a catalyst for the hydrogenation of ketones but at a catalyst loading of $5 \mathrm{~mol} \%$, a temperature of $130{ }^{\circ} \mathrm{C}$ in the presence of $10 \mathrm{~mol} \%$ base, and a hydrogen pressure of $50 \mathrm{bar}$ in toluene as solvent. ${ }^{10 \mathrm{~d}}$

The alternative mechanism (path II) shares the first part in Figure 1 until formation of the cationic intermediate $\mathbf{C}$. Following the profile represented in Figure 4, addition of $\mathrm{H}_{2}$ to $\mathbf{C}$ yields intermediate $\mathbf{K}$. From here, coordination of dihydrogen is easy, with a barrier of merely $1 \mathrm{kcal} / \mathrm{mol}\left(\mathrm{TS}_{\mathrm{KL}}\right)$ in an exergonic step $(\Delta G=-8 \mathrm{kcal} / \mathrm{mol})$. The difference between the two mechanisms is that while here $\mathrm{H}_{2}$ coordinates to complex $\left[\mathrm{Mn}(\mathrm{PNP})(\mathrm{CO})_{2}\right]^{+}$, producing the cationic dihydrogen complex $\left[\mathrm{Mn}(\mathrm{PNP})\left(\eta^{2}-\mathrm{H}_{2}\right)(\mathrm{CO})_{2}\right]^{+}$, in path I that process occurs with the neutral metallic species $\left[\mathrm{Mn}\left(\mathrm{PNP}^{\prime}\right)(\mathrm{CO})_{2}\right]$, featuring a deprotonated $\mathrm{PNP}$ ligand $\left(\mathrm{PNP}^{\prime}\right)$, and yields the corresponding neutral $\mathrm{H}_{2}$ complex: $\left[\mathrm{Mn}\left(\mathrm{PNP}^{\prime}\right)\left(\eta^{2}-\mathrm{H}_{2}\right)(\mathrm{CO})_{2}\right]$. The mechanism proceeds from $\mathrm{L}$ with protonation of the free alkoxide by means of the coordinated $\mathrm{H}_{2}$. The associated barrier $\left(\mathrm{TS}_{\mathrm{LM}}\right)$ is negligible $(1 \mathrm{kcal} / \mathrm{mol})$, and the resulting species $(\mathbf{M})$ is $13 \mathrm{kcal} /$ 


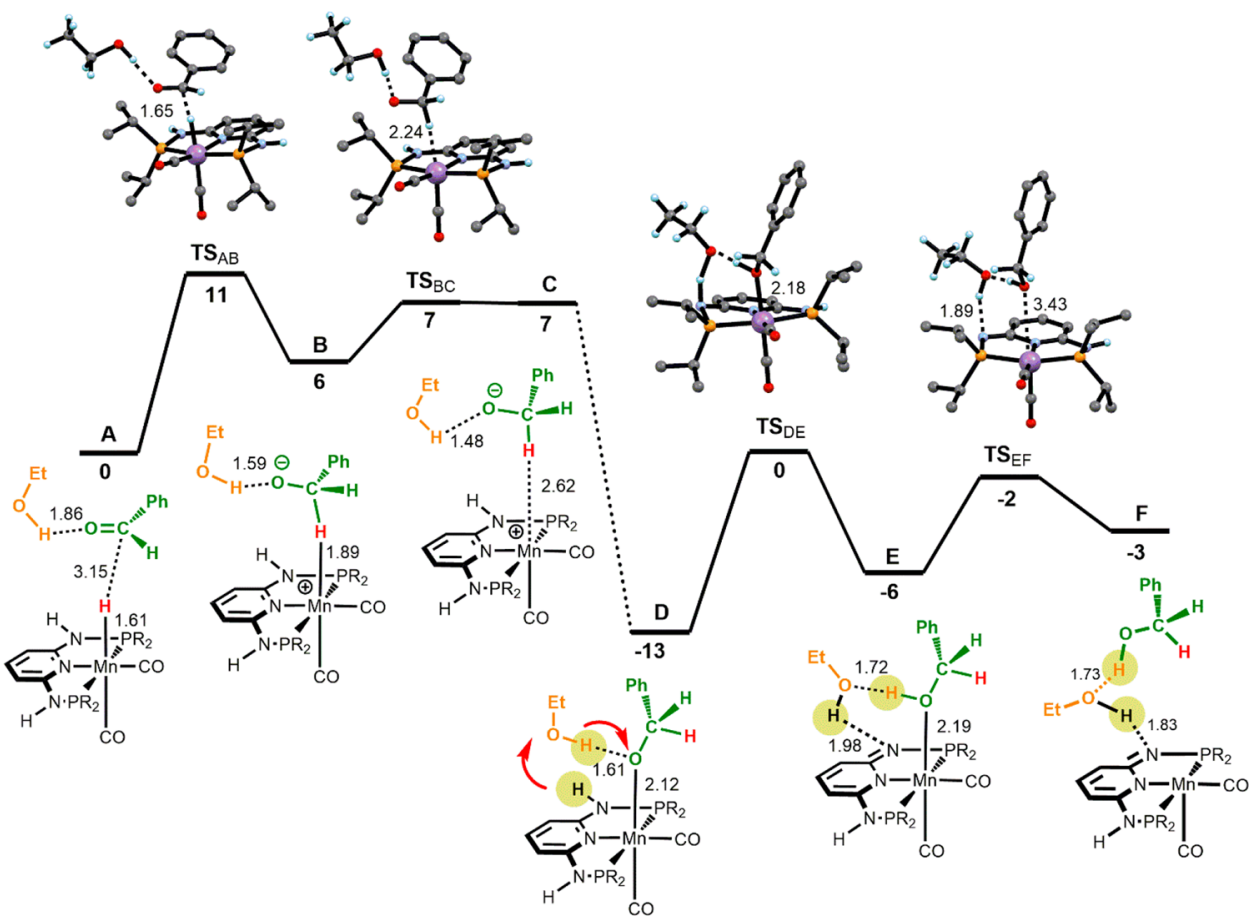

Figure 1. Free energy profile calculated for the hydrogenation of benzaldehyde catalyzed by the hydride complex $\mathbf{A}$ with ligand $\mathrm{N}-\mathrm{H}$ bond participation . Free energies $(\mathrm{kcal} / \mathrm{mol})$ are referred to the initial reactants $(\mathbf{A})$, and relevant distances $(\AA)$ are presented.

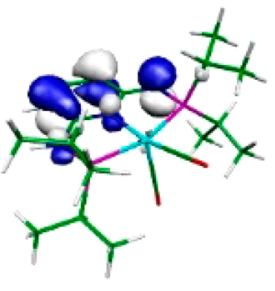

HOMO

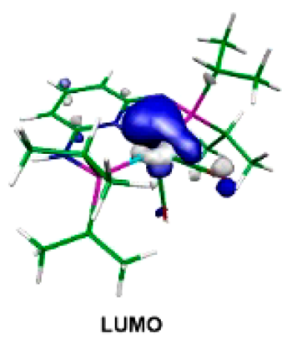

Figure 2. HOMO and LUMO of deprotonated Mn1 (F in calculations).

mol more stable than A. The highest barrier in path II is $26 \mathrm{kcal} /$ mol, measured between the O-coordinated alkoxide complex D and the highest following transition state $\mathbf{T S}_{\mathrm{KL}}$. This is the transition state associated with $\mathrm{H}_{2}$ coordination and formation of the dihydrogen complex in $\mathbf{L}$. It has to be noted that the same reaction pathway was recently established for the chemoselective hydrogenation of aldehydes catalyzed by $\left[\mathrm{Fe}\left(\mathrm{PNP}^{\mathrm{Me}}{ }_{-} \mathrm{Pr}\right)(\mathrm{CO})\right.$ $(\mathrm{H})(\mathrm{Br})$ ], where metal-ligand cooperation was not possible due NMe linkers. ${ }^{15}$

In path $\mathrm{I}$, alkoxide protonation is accomplished by the $\mathrm{N}-\mathrm{H}$ proton in the PNP ligand, yielding a metallic fragment with a dearomatized PNP ligand. This corresponds to a bifunctional mechanism with participation of the PNP ligand that is further regenerated by the coordinated $\mathrm{H}_{2}$ molecule. In path II, there is no participation of the PNP ligand, and alkoxide protonation is made directly by the coordinated $\mathrm{H}_{2}$ molecule. The difference between the highest barriers calculated for the two mechanisms is

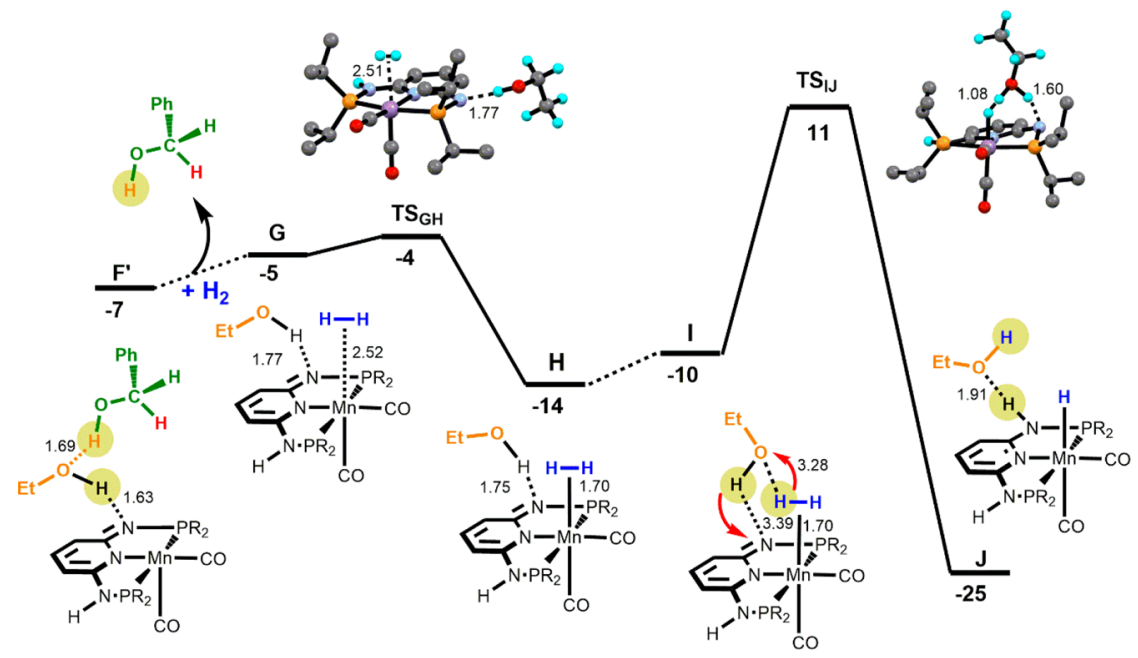

Figure 3. Free energy profile calculated for the hydrogenation of benzaldehyde catalyzed by the hydride complex $\mathbf{A}$ in a bifunctional mechanism with ligand $\mathrm{N}-\mathrm{H}$ bond participation. The free energy values $(\mathrm{kcal} / \mathrm{mol})$ are referred to the initial reactants $(\mathbf{A})$, and relevant distances $(\AA)$ are presented. 


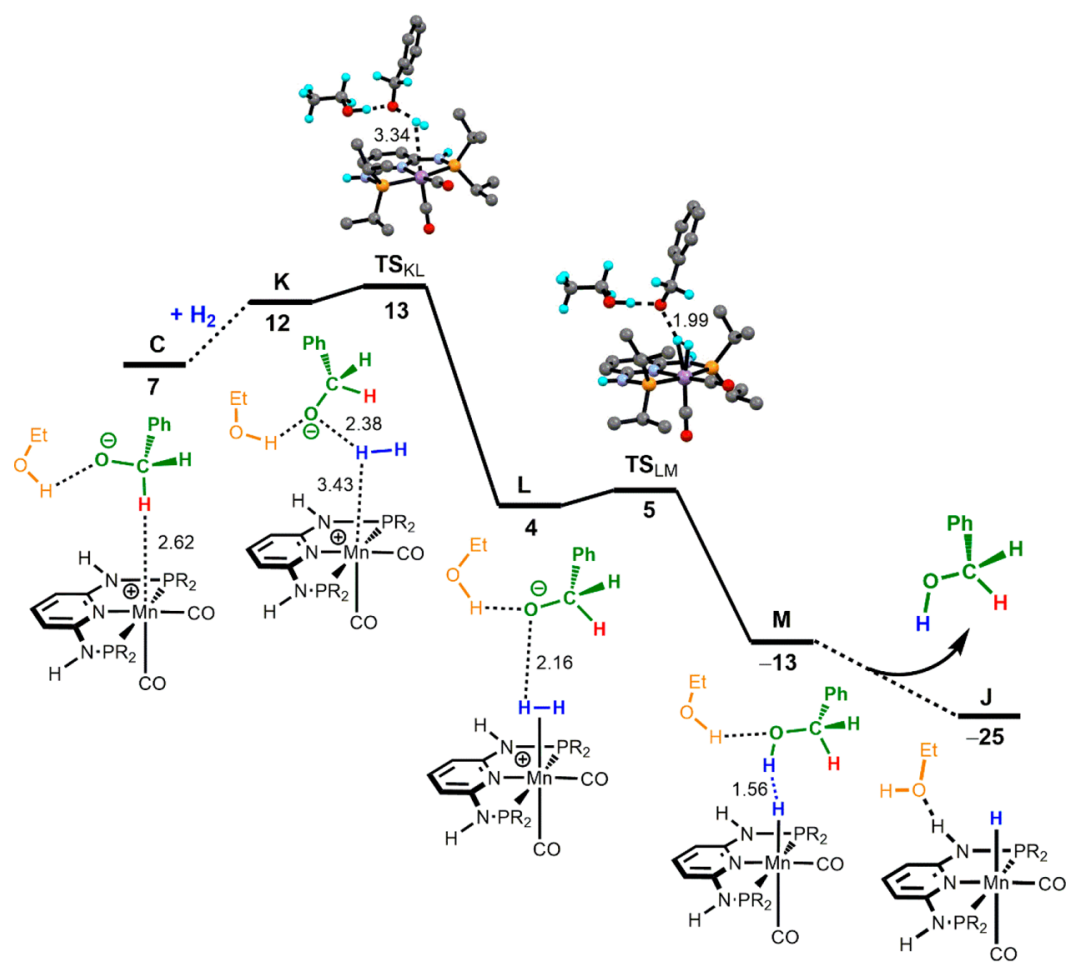

Figure 4. Free energy profile calculated for the hydrogenation of benzaldehyde catalyzed by the hydride complex $\mathbf{A}$ without ligand $N-H$ bond participation. The free energy values $(\mathrm{kcal} / \mathrm{mol})$ are referred to the initial reactants $(\mathbf{A})$, and relevant distances $(\AA)$ are presented.

only $1 \mathrm{kcal} / \mathrm{mol}$ ( $25 \mathrm{kcal} / \mathrm{mol}$ for path I, $26 \mathrm{kcal} / \mathrm{mol}$ for path II); thus, in principle, both could occur under the experimental conditions. If entropy corrections for non-standard conditions are considered, the total barrier for path I rises to $26.5 \mathrm{kcal} / \mathrm{mol}$ due to the lower molecularity of $\mathbf{T S}_{\mathrm{IJ}}$ when compared to $\mathbf{T S}_{\mathrm{KL}}$ and to the reaction conditions. This makes path I slightly less favorable than path II.

\section{CONCLUSION}

Several hydride $\mathrm{Mn}(\mathrm{I})$ and $\mathrm{Re}(\mathrm{I})$ PNP pincer complexes were prepared and tested as catalysts for the homogeneous chemoselective hydrogenation of aldehydes. [Mn(PNP-iPr)$\left.(\mathrm{CO})_{2}(\mathrm{H})\right](\mathrm{Mn} \mathbf{1})$, based on the 2,6-diaminopyridine scaffold, where the $\mathrm{PiPr}_{2}$ moieties of the PNP ligand connect to the pyridine ring via $\mathrm{NH}$ linkers, was found to be the most efficient catalyst for this process. The reaction is highly chemoselective also in the presence of other functional groups which can be hydrogenated, such as ketones, esters, alkynes, olefins, nitriles, and $\alpha, \beta$-unsaturated double bonds. The low catalyst loadings (0.1-0.05 mol\%), mild and base-free reaction conditions $\left(25^{\circ} \mathrm{C}\right.$, 50 bar $\mathrm{H}_{2}$ ), and broad applicability make this catalyst interesting for the syntheses of fine and bulk chemicals. The catalysis works also with lower catalyst loadings $(0.005 \mathrm{~mol} \%)$ but requires then the addition of an external base. Based on experimental and computational studies, a bifunctional mechanism with participation of the PNP ligand (deprotonation/protonation) is proposed. An alternative mechanism without participation of the PNP ligand cannot be fully dismissed but seems to be less likely. Surprisingly, analogous isoelectronic and isostructural $\operatorname{Re}(\mathrm{I})$ complexes turned out to be only poorly active.

\section{ASSOCIATED CONTENT}

\section{Supporting Information}

The Supporting Information is available free of charge on the ACS Publications website at DOI: 10.1021/acscatal.8b00153.

Complete crystallographic data, ${ }^{1} \mathrm{H},{ }^{13} \mathrm{C}\left\{{ }^{1} \mathrm{H}\right\}$, and ${ }^{31} \mathrm{P}\left\{{ }^{1} \mathrm{H}\right\}$ NMR spectra of all new complexes, and computational details (PDF)

Crystallographic details for Re1 (CCDC entry 1815730) (CIF)

Coordinates of all optimized species (XYZ)

\section{AUTHOR INFORMATION}

\section{Corresponding Author}

*E-mail: karl.kirchner@tuwien.ac.at. Tel.: (+43) 158801 163611. Fax: (+43) 15880116399.

ORCID 웅

Karl Kirchner: 0000-0003-0872-6159

Notes

The authors declare no competing financial interest.

\section{ACKNOWLEDGMENTS}

Financial support by the Austrian Science Fund (FWF) is gratefully acknowledged (Project No. P29584-N28). L.F.V. acknowledges Fundação para a Ciência e Tecnologia, Projecto Estratégico - PEst-OE/QUI/UI0100/2013.

\section{REFERENCES}

(1) (a) de Vries, J. G., Elsevier, C. J., Eds. Handbook of Homogeneous Hydrogenation; Wiley-VCH: Weinheim, 2007. (b) Dupau, P. In Organometallics as Catalysts in the Fine Chemical Industry; Beller, M., Blaser, H. U., Eds.; Springer-Verlag: Berlin, 2012. (c) Johnson, N. B.; Lennon, I. C.; Moran, P. H.; Ramsden, J. A. Industrial-Scale Synthesis and Applications of Asymmetric Hydrogenation Catalysts. Acc. Chem. 
Res. 2007, 40, 1291-1299. (d) Dub, P. A.; Ikariya, T. Catalytic Reductive Transformations of Carboxylic and Carbonic Acid Derivatives Using Molecular Hydrogen. ACS Catal. 2012, 2, 1718-1741.

(2) (a) Noyori, R.; Ohkuma, T. Rapid, productive and stereoselective hydrogenation of ketones. Pure Appl. Chem. 1999, 71, 1493-1501. (b) Noyori, R; Ohkuma, T. Asymmetric Catalysis by Architectural and Functional Molecular Engineering: Practical Chemo- and Stereoselective Hydrogenation of Ketones. Angew. Chem., Int. Ed. 2001, 40, 40-73. (c) Noyori, R. Asymmetric Catalysis: Science and Opportunities (Nobel Lecture). Angew. Chem., Int. Ed. 2002, 41, 2008-2022. (d) Ohkuma, H.; Ooka, T.; Ikariya, R.; Noyori, R. Preferential hydrogenation of aldehydes and ketones. J. Am. Chem. Soc. 1995, 117, 10417-10418. (e) Baldino, S.; Facchetti, S.; Zanotti-Gerosa, A.; Nedden, H. G.; Baratta, W. Transfer Hydrogenation and Hydrogenation of Commercial-Grade Aldehydes to Primary Alcohols Catalyzed by 2(Aminomethyl)pyridine and Pincer Benzo[h]quinoline Ruthenium Complexes. Chem CatChem 2016, 8, 2279-2288.

(3) Bonomo, L.; Kermorvan, L.; Dupau, P. Ruthenium-Catalyzed Highly Chemoselective Hydrogenation of Aldehydes. ChemCatChem 2015, 7, 907-910.

(4) (a) Casey, C. P.; Strotman, N. A.; Beetner, S. E.; Johnson, J. B.; Priebe, D. C.; Guzei, I. A. $\mathrm{PPh}_{3}$-Substituted $\left[2,5-\mathrm{Ph}_{2}-3,4-\mathrm{Tol}_{2}\left(\eta^{5}-\right.\right.$ $\left.\left.\mathrm{C}_{4} \mathrm{COH}\right)\right] \mathrm{Ru}(\mathrm{CO})\left(\mathrm{PPh}_{3}\right) \mathrm{H}$ Exhibits Slower Stoichiometric Reduction, Faster Catalytic Hydrogenation, and Higher Chemoselectivity for Hydrogenation of Aldehydes over Ketones Than the Dicarbonyl Shvo Catalyst. Organometallics 2006, 25, 1236-1244. (b) Diab, L.; Smejkal, T.; Geier, J.; Breit, B. Supramolecular Catalyst for Aldehyde Hydrogenation and Tandem Hydroformylation-Hydrogenation. Angew. Chem., Int. Ed. 2009, 48, 8022-8026.

(5) (a) Surburg, H., Panten, J., Eds. Common Fragrance and Flavor Materials; Wiley-VCH: Weinheim, 2006. (b) Saudan, L. A. Hydrogenation Processes in the Synthesis of Perfumery Ingredients. Acc. Chem. Res. 2007, 40, 1309-1319.

(6) (a) Smith, A. B.; Barbosa, J.; Wong, W.; Wood, J. L. Total Syntheses of (+)-Trienomycins A and F via a Unified Strategy. J. Am. Chem. Soc. 1996, 118, 8316-8328. (b) Kobayakawa, Y.; Nakada, M. J. Enantioselective total synthesis of (A)-cyathin B2. J. Antibiot. 2014, 67, 483-485.

(7) Bullock, R. M., Ed. Catalysis Without Precious Metals; Wiley-VCH: Weinheim, 2010.

(8) (a) Maji, B.; Barman, M. K. Recent Developments of Manganese Complexes for Catalytic Hydrogenation and Dehydrogenation Reactions. Synthesis 2017, 49, 3377-3393. (b) Garbe, M.; Junge, K.; Beller, M. Homogeneous Catalysis by Manganese-Based Pincer Complexes. Eur. J. Org. Chem. 2017, 2017, 4344-4362. (c) Kallmeier, F.; Kempe, R. Manganese Complexes for (De)Hydrogenation Catalysis: A Comparison to Cobalt and Iron Catalysts. Angew. Chem., Int. Ed. 2018, 57, 46-60. (d) Zell, T.; Langer, R. From ruthenium to iron and manganese - a mechanistic view on challenges and design principles of base metal hydrogenation catalysts. ChemCatChem 2018, DOI: $10.1002 /$ cctc.201701722. (e) Filonenko, G. A.; van Putten, R.; Hensen, E. J. M.; Pidko, E. A. Catalytic (de)hydrogenation promoted by non-precious metals - $\mathrm{Co}, \mathrm{Fe}$ and $\mathrm{Mn}$ : recent advances in an emerging field. Chem. Soc. Rev. 2018, 47, 1459-1483.

(9) Fe-catalyzed hydrogenation reactions: (a) Federsel, C.; Boddien, A.; Jackstell, R.; Jennerjahn, R.; Dyson, P. J.; Scopelliti, R.; Laurenczy, G.; Beller, M. A Well-Defined Iron Catalyst for the Reduction of Bicarbonates and Carbon Dioxide to Formates, Alkyl Formates, and Formamides. Angew. Chem., Int. Ed. 2010, 49, 9777-9780. (b) Langer, R.; Leitus, G.; Ben-David, Y.; Milstein, D. Efficient hydrogenation of ketones catalyzed by an iron pincer complex. Angew. Chem., Int. Ed. 2011, 50, 2120-2124. (c) Langer, R; Iron, M. A.; Konstantinovski, L.; Diskin-Posner, Y.; Leitus, G.; Ben-David, Y.; Milstein, D. Iron Borohydride Pincer Complexes for the Efficient Hydrogenation of Ketones under Mild, Base-Free Conditions: Synthesis and Mechanistic Insight. Chem. - Eur. J. 2012, 18, 7196-7209. (d) Ziebart, C.; Federsel, C.; Anbarasan, P.; Jackstell, R.; Baumann, W.; Spannenberg, A.; Beller, M. Well-Defined Iron Catalyst for Improved Hydrogenation of Carbon Dioxide and Bicarbonate. J. Am. Chem. Soc. 2012, 134, 20701-20704. (e) Fleischer, S.; Zhou, S.; Junge, K.; Beller, M. General and Highly Efficient Iron-Catalyzed Hydrogenation of Aldehydes, Ketones, and $\alpha, \beta$-Unsaturated Aldehydes. Angew. Chem., Int. Ed. 2013, 52, 51205124. (f) Srimani, D.; Diskin-Posner, Y.; Ben-David, Y.; Milstein, D. Iron Pincer Complex Catalyzed, Environmentally Benign, E-Selective Semi-Hydrogenation of Alkynes. Angew. Chem., Int. Ed. 2013, 52, 14131-14134. (g) Wienhofer, G.; Baseda-Kruger, M.; Ziebart, C.; Westerhaus, F. A.; Baumann, W.; Jackstell, R.; Junge, K.; Beller, M. Hydrogenation of nitroarenes using defined iron-phosphine catalysts. Chem. Commun. 2013, 49, 9089-9091. (h) Bornschein, C.; Werkmeister, S.; Wendt, B.; Jiao, H.; Alberico, E.; Baumann, W.; Junge, H.; Junge, K.; Beller, M. Mild and selective hydrogenation of aromatic and aliphatic (di)nitriles with a well-defined iron pincer complex. Nat. Commun. 2014, 5, 4111. (i) Chakraborty, S.; Dai, H.; Bhattacharya, P.; Fairweather, N. T.; Gibson, M. S.; Krause, J. A.; Guan, H. Iron-Based Catalysts for the Hydrogenation of Esters to Alcohols. J. Am. Chem. Soc. 2014, 136, 7869-7872. (j) Chakraborty, S.; Lagaditis, P. O.; Förster, M.; Bielinski, E. A.; Hazari, N.; Holthausen, M. C.; Jones, W. D.; Schneider, S. Well-Defined Iron Catalysts for the Acceptorless Reversible Dehydrogenation-Hydrogenation of Alcohols and Ketones. ACS Catal. 2014, 4, 3994-4003. (k) Lagaditis, P. O.; Sues, P. E.; Sonnenberg, J. E.; Wan, K. Y.; Lough, A. J.; Morris, R. H. Iron(II) Complexes Containing Unsymmetrical P-N-P' Pincer Ligands for the Catalytic Asymmetric Hydrogenation of Ketones and Imines. J. Am. Chem. Soc. 2014, 136, 1367-1380. (1) Werkmeister, S.; Junge, K.; Wendt, B.; Alberico, E.; Jiao, H.; Baumann, W.; Junge, H.; Gallou, F.; Beller, M. Hydrogenation of Esters to Alcohols with a Well-Defined Iron Complex. Angew. Chem., Int. Ed. 2014, 53, 8722-8726. (m) Bertini, F.; Mellone, I.; Ienco, A.; Peruzzini, M.; Gonsalvi, L. Iron(II) Complexes of the Linear rac-Tetraphos-1 Ligand as Efficient Homogeneous Catalysts for Sodium Bicarbonate Hydrogenation and Formic Acid Dehydrogenation. ACS Catal. 2015, 5, 1254-1265. (n) Rivada-Wheelaghan, O.; Dauth, A.; Leitus, G.; Milstein, D.; Diskin-Posner, Y. Synthesis and Reactivity of Iron Complexes with a New Pyrazine-Based Pincer Ligand, and Application in Catalytic Low-Pressure Hydrogenation of Carbon Dioxide. Inorg. Chem. 2015, 54, 4526-4538. (o) Zhang, Y.; MacIntosh, A. D.; Wong, J. L.; Bielinski, E. A.; Williard, P. G.; Mercado, B. Q.; Hazari, N.; Bernskoetter, W. H. Iron catalyzed $\mathrm{CO}_{2}$ hydrogenation to formate enhanced by Lewis acid co-catalysts. Chem. Sci. 2015, 6, 42914299. (p) Gorgas, N.; Stöger, B.; Veiros, L. F.; Pittenauer, E.; Allmaier, G.; Kirchner, K. Efficient Hydrogenation of Ketones and Aldehydes Catalyzed by Well-Defined Iron(II) PNP Pincer Complexes: Evidence for an Insertion Mechanism. Organometallics 2014, 33, 6905-6914.

(10) Mn-catalyzed hydrogenations of ketones and aldehydes: (a) Elangovan, S.; Topf, C.; Fischer, S.; Jiao, H.; Spannenberg, A.; Baumann, W.; Ludwig, R.; Junge, K.; Beller, M. Selective Catalytic Hydrogenations of Nitriles, Ketones, and Aldehydes by Well-Defined Manganese Pincer Complexes. J. Am. Chem. Soc. 2016, 138, 8809-8814. (b) Kallmeier, F.; Irrgang, T.; Dietel, T.; Kempe, R. Highly Active and Selective Manganese $\mathrm{C}=\mathrm{O}$ Bond Hydrogenation Catalysts: The Importance of the Multidentate Ligand, the Ancillary Ligands, and the Oxidation State. Angew. Chem., Int. Ed. 2016, 55, 11806-11809. (c) Widegren, M. B.; Harkness, G. J.; Slawin, A. M. Z.; Cordes, D. B.; Clarke, M. L. A Highly Active Manganese Catalyst for Enantioselective Ketone and Ester Hydrogenation. Angew. Chem., Int. Ed. 2017, 56, 5825-5828. (d) Bruneau-Voisine, A.; Wang, D.; Roisnel, T.; Darcel, C.; Sortais, J.-P. Hydrogenation of ketones with a manganese $\mathrm{PN}^{3} \mathrm{P}$ pincer pre-catalyst. Catal. Commun. 2017, 92, 1-4. (e) Garbe, M.; Junge, K.; Walker, S.; Wei, Z.; Jiao, H.; Spannenberg, A.; Bachmann, S.; Scalone, M.; Beller, M. Manganese(I)-Catalyzed Enantioselective Hydrogenation of Ketones Using a Defined Chiral PNP Pincer Ligand. Angew. Chem., Int. Ed. 2017, 56, 11237-11241.

(11) (a) Perez, M.; Elangovan, S.; Spannenberg, A.; Junge, K.; Beller, M. Molecularly Defined Manganese Pincer Complexes for Selective Transfer Hydrogenation of Ketones. ChemSusChem 2017, 10, 83-86. (b) Zirakzadeh, A.; de Aguiar, S. R. M. M.; Stöger, B.; Widhalm, M.; Kirchner, K. Enantioselective Transfer Hydrogenation of Ketones Catalyzed by a Manganese Complex Containing an Unsymmetrical Chiral PNP' Tridentate Ligand. ChemCatChem 2017, 9, 1744-1748. 
(c) Espinosa-Jalapa, N. A.; Nerush, A.; Shimon, L. J. W.; Leitus, G.; Avram, L.; Ben-David, Y.; Milstein, D. Manganese-Catalyzed Hydrogenation of Esters to Alcohols. Chem. - Eur. J. 2017, 23, 5934-5938. (d) Elangovan, S.; Garbe, M.; Jiao, H.; Spannenberg, A.; Junge, K.; Beller, M. Non-Pincer-Type Manganese Complexes as Efficient Catalysts for the Hydrogenation of Esters. Angew. Chem. 2016, 128, 15590-15594. (e) Bertini, F.; Glatz, M.; Gorgas, N.; Stöger, B.; Peruzzini, M.; Veiros, L. F.; Kirchner, K.; Gonsalvi, L. Carbon dioxide hydrogenation catalysed by well-defined $\mathrm{Mn}(\mathrm{I}) \mathrm{PNP}$ pincer hydride complexes. Chem. Sci. 2017, 8, 5024-5029. (f) van Putten, R.; Uslamin, E. A.; Garbe, M.; Liu, C.; Gonzalez-de-Castro, A.; Lutz, M.; Junge, K.; Hensen, E. J. M.; Beller, M.; Lefort, L.; Pidko, E. A. Non-Pincer-Type Manganese Complexes as Efficient Catalysts for the Hydrogenation of Esters. Angew. Chem., Int. Ed. 2017, 56, 7531-7534. (g) Kar, S.; Goeppert, A.; Kothandaraman, J.; Prakash, G. K. S. ManganeseCatalyzed Sequential Hydrogenation of $\mathrm{CO}_{2}$ to Methanol via Formamide. ACS Catal. 2017, 7, 6347-6351.

(12) Wienhofer, G.; Westerhaus, F. A.; Junge, K.; Ludwig, R.; Beller, M. A Molecularly Defined Iron-Catalyst for the Selective Hydrogenation of $\alpha, \beta$-Unsaturated Aldehydes. Chem. - Eur. J. 2013, 19, 7701-7707.

(13) Zell, T.; Ben-David, Y.; Milstein, D. Highly efficient, general hydrogenation of aldehydes catalyzed by PNP iron pincer complexes. Catal. Sci. Technol. 2015, 5, 822-826.

(14) Mazza, S.; Scopelliti, R.; Hu, X. Chemoselective Hydrogenation and Transfer Hydrogenation of Aldehydes Catalyzed by Iron(II) PONOP Pincer Complexes. Organometallics 2015, 34, 1538-1545.

(15) (a) Gorgas, N.; Stöger, B.; Veiros, L. F.; Kirchner, K. Highly Efficient and Selective Hydrogenation of Aldehydes: A Well-Defined Iron(II) Catalyst exhibits Noble Metal Activity. ACS Catal. 2016, 6, 2664-2672. (b) Brünig, J.; Csendes, Z.; Weber, S.; Gorgas, N.; Bittner, R. W.; Limbeck, A.; Bica, K.; Hoffmann, H.; Kirchner, K. Chemoselective Supported Ionic Liquid Phase (SILP) Aldehyde Hydrogenation Catalyzed by an Fe(II) PNP Pincer Complex. ACS Catal. 2018, $8,1048-1051$.

(16) Wei, D.; Roisnel, T.; Darcel, C.; Clot, E.; Sortais, J.-B. Hydrogenation of Carbonyl Derivatives with a Well-Defined Rhenium Precatalyst. Chem CatChem 2017, 9, 80-83.

(17) For rhenium-catalyzed (de)hydrogenation reactions, see: (a) Piehl, P.; Pena-Lopez, M.; Frey, A.; Neumann, H.; Beller, M. Hydrogen autotransfer and related dehydrogenative coupling reactions using a rhenium(I) pincer catalyst. Chem. Commun. 2017, 53, 32653268. (b) Schleker, P. P. M.; Honeker, R.; Klankermayer, J.; Leitner, W. Catalytic Dehydrogenative Amide and Ester Formation with RheniumTriphos Complexes. ChemCatChem 2013, 5, 1762-1764. (c) Jin, H.; Xie, J.; Pan, C.; Zhu, Z.; Cheng, Y.; Zhu, C. Rhenium-Catalyzed Acceptorless Dehydrogenative Coupling via Dual Activation of Alcohols and Carbonyl Compounds. ACS Catal. 2013, 3, 2195-2198. (d) Vogt, M.; Nerush, A.; Iron, M. A.; Leitus, G.; Diskin-Posner, Y.; Shimon, L. J. W.; Ben-David, Y.; Milstein, D. Activation of Nitriles by Metal Ligand Cooperation. Reversible Formation of Ketimido- and EnamidoRhenium PNP Pincer Complexes and Relevance to Catalytic Design. J. Am. Chem. Soc. 2013, 135, 17004-17018. (e) Abdukader, A.; Jin, H.; Cheng, Y.; Zhu, C. Rhenium-catalyzed amination of alcohols by hydrogen transfer process. Tetrahedron Lett. 2014, 55, 4172-4174. (f) Vogt, M.; Nerush, A.; Diskin-Posner, Y.; Ben-David, Y.; Milstein, D. Reversible $\mathrm{CO}_{2}$ binding triggered by metal-ligand cooperation in a rhenium(I) PNP pincer-type complex and the reaction with dihydrogen. Chemi. Sci. 2014, 5, 2043-2051. (g) Mazzotta, M. G.; Xiong, M.; AbuOmar, M. M. Carbon Dioxide Reduction to Silyl-Protected Methanol Catalyzed by an Oxorhenium Pincer PNN Complex. Organometallics 2017, 36, 1688-1691.

(18) (a) Rao, G. K.; Korobkov, I.; Gabidullin, B.; Richeson, D. Employing a neutral "PN3P" pincer to access mer-Re(I) tricarbonyl complexes: Autoionization of a halo ligand and the role of an N-R $(\mathrm{R}=$ H, Me) substituent. Polyhedron 2018, 143, 62-69. (b) Choualeb, A.; Maccaroni, E.; Blacque, O.; Schmalle, H. W.; Berke, H. Rhenium Nitrosyl Complexes for Hydrogenations and Hydrosilylations. Organometallics 2008, 27, 3474-3481.
(19) (a) Mastalir, M.; Glatz, M.; Gorgas, N.; Stöger, B.; Pittenauer, E.; Allmaier, G.; Veiros, L. F.; Kirchner, K. Divergent Coupling of Alcohols and Amines Catalyzed by Isoelectronic Hydride $\mathrm{Mn}^{\mathrm{I}}$ and $\mathrm{Fe}^{\mathrm{II}} \mathrm{PNP}$ Pincer Complexes. Chem. - Eur. J. 2016, 22, 12316-12320. (b) Mastalir, M.; Glatz, M.; Pittenauer, E.; Allmaier, G.; Kirchner, K. Sustainable Synthesis of Quinolines and Pyrimidines Catalyzed by Manganese PNP Pincer Complexes. J. Am. Chem. Soc. 2016, 138, 15543-15546. (c) Mastalir, M.; Pittenauer, E.; Allmaier, G.; Kirchner, K. ManganeseCatalyzed Aminomethylation of Aromatic Compounds with Methanol as Sustainable C1 Building Block. J. Am. Chem. Soc. 2017, 139, 88128815.

(20) (a) Parr, R. G.; Yang, W. Density Functional Theory of Atoms and Molecules; Oxford University Press: New York, 1989. (b) Free energy values were obtained at the PBE0/VDZP level using the Gaussian 09 package. All calculations included solvent effects (ethanol) using the PCM/SMD model. A full account of the computational details and a complete list of references are provided as SI..

(21) Morello, G. R.; Hopmann, K. H. A Dihydride Mechanism Can Explain the Intriguing Substrate Selectivity of Iron-PNP-Mediated Hydrogenation. ACS Catal. 2017, 7, 5847-5855. 